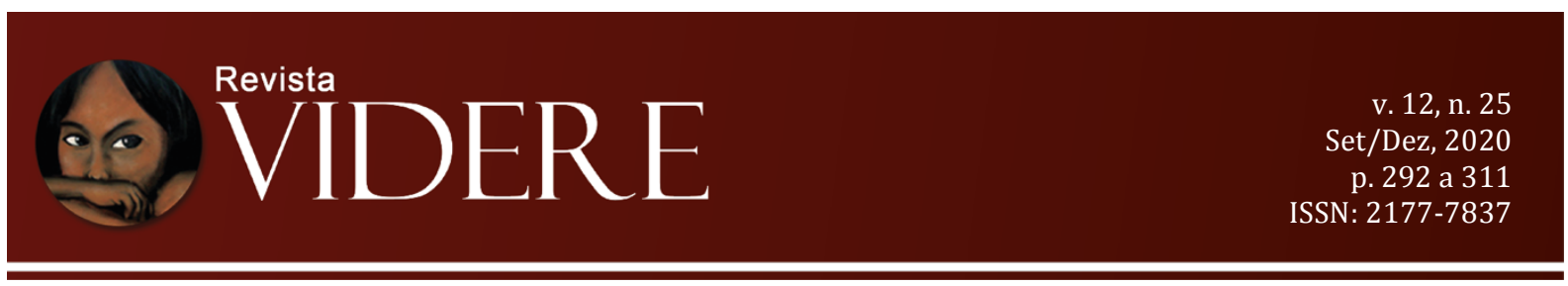

\title{
A INSUFICIÊNCIA DA TUTELA JURÍDICA DAS IDENTIDADES HUMANAS E A NECESSIDADE DE FLEXIONAR FRONTEIRAS
}

\author{
THE INSUFFICIENCY OF LEGAL TREATMENT OF HUMAN IDENTITIES AND THE \\ TO FLEXIBILIZE BORDERS
}

\section{LA INSUFICIENCIA DE GARANTÍA JURÍDICA DE IDENTIDADES HUMANAS Y LA NECESIDAD DE FLEXIONAR LAS FRONTERAS}

Doutoranda em Direito pela Universidade Federal do Paraná (UFPR). Graduada e Mestre em Direito pela Universidade Federal de Santa Maria/RS (UFSM). Docente no Curso de Direito do Centro Universitário Univel, em Cascavel-PR. danigadenz@gmail.com

OrcidID: https://orcid.org/0000-0002-5365-7159

Resumo: O presente artigo propõe discutir a formação e regulação jurídica da(s) identidade(s) a partir do viés de gênero, analisando como a questão identitária é tratada pelo direito brasileiro, a fim de expor as discrepâncias existentes entre a realidade e a regulação jurídica. A formação e tutela da identidade a partir da perspectiva binária de gênero reforça a delimitação de fronteiras e evidencia a precariedade da visão jurídica da identidade, reflexo da matriz heteronormativa. São oferecidas críticas a essas aparentes desconformidades identitárias, de modo a demonstrar a urgência em situar aqueles que se encontram fora das fronteiras como sujeitos de direito merecedores da mesma proteção que é garantida a todos os cidadãos. Utiliza-se do método dedutivo, partindo-se da percepção moderna de identidade para o direito e analisando seus reflexos quanto à tutela relativa ao âmbito de gênero, em uma abordagem a partir da crítica feminista à heteronormatividade e à designação binária de identidade.

Palavras-chave: Identidades. Lógica categorial moderna. Gênero. Fronteiras. Humanidade.

ABSTRACT: This article proposes to discuss the formation and legal regulation of identity(ies) from a gender perspective, analyzing how the identity issue is treated by brazilian law, in order to expose the discrepancies between reality and legal regulation. The formation and protection of identity from a gender binary perspective reinforces the delimitation of borders and highlights the precariousness of the legal vision of identity, as a reflection of the heteronormative foundation. Criticisms are offered to these identity apparent misconceptions, in order to demonstrate the urgency in situating those outside the borders as subjects of law 
deserving the same protection that is guaranteed to all citizens. Is used the deductive method, starting from the modern perception of identity by the law and analyzing the reflexes regarding the protection related to the gender, in an approach based on the feminist criticism of heteronormativity and the binary identity designation.

KEYWORDS: Identities; Modern Categorical Logic; Gender; Borders; Humanity.

Abstract: Este artículo tiene como objetivo discutir la formación y la regulación juridica de la(s) identidad(s) desde una perspectiva de género, analizando cómo la ley brasileña trata el tema de la identidad, para exponer las discrepancias existentes entre la realidad y regulación. La formación y protección de la identidad desde una perspectiva binaria de género refuerza la delimitación de las fronteras y destaca la precariedad de la visión legal de la identidad reflejo de la matriz heteronormativa. Se intentó ofrecer a estas identidades em desacuerdo un análisis crítico que demuestra la urgencia de reconocer a los que están fuera de las fronteras su calidad de sujetos de derecho que merecen la misma protección garantizada a los otros ciudadanos. Utiliza el método deductivo, partiendo de la percepción moderna de identidad a la ley y analizando sus reflejos con respecto a la tutela relacionada con el alcance de género, en un enfoque basado en la crítica feminista de la heteronormatividad y la designación de identidad binaria.

Keywords: Identidades. Logica categorial moderna. Gênero. Fronteras. Humanidad.

\section{Introdução}

Diversos ramos das ciências humanas, ao analisar as transformações nas paisagens culturais de classe, sexualidade, etnia, raça e outras, que historicamente servem de base para a localização social dos indivíduos, descrevem concepções enraizadas, ligadas a um paradigma de estabilidade e coerência da identidade (HALL, 2009). No entanto, tal estabilidade não coaduna com a realidade das identidades humanas, pois "algo que se supõe ser fixo, coerente e estável é deslocado pela experiência da dúvida e da incerteza" (WOODWARD, 2014, p. 20).

A categoria "gênero" foi, ao longo dos séculos, social e juridicamente utilizada como delimitadora da identidade, contribuindo para a perpetuação de crenças epistemológicas próprias da modernidade, divisões sociais baseadas na dicotomia masculino/feminino e suas derivações.

Nessa perspectiva, o presente artigo propõe-se discutir a formação e regulação jurídica da(s) identidade(s) a partir do viés de gênero, lendo, a partir da genealogia foucaultiana, a divisão sexual da sociedade como um reflexo da estruturação das relações de poder. 
Objetiva-se, a partir da análise do tratamento da questão identitária pelo direito brasileiro, expor as discrepâncias existentes entre a realidade e a maneira pela qual as identidades são reguladas e fixadas juridicamente no que tange ao delimitador "gênero". Discutem-se, portanto, as fronteiras estabelecidas pela categorização identitária e como elas negam humanidade aos indivíduos.

Para tanto, utiliza-se do método dedutivo, partindo-se da percepção moderna de identidade, absorvida pelo direito, analisando seus reflexos na tutela relativa ao gênero e transversalizando a abordagem a partir da crítica feminista à heteronormatividade e aos padrões binários de identidade, notadamente com apoio na teoria queer.

Assim, o presente estudo foi estruturado em três capítulos. Inicialmente, será exposto como o direito regula a identidade dos indivíduos e quais aspectos vêm sendo debatidos pelo direito brasileiro acerca da questão. Na sequência, o fenômeno identitário será abordado em seu viés sociológico, a fim de tensionar os limites do direito frente à realidade dos indivíduos cujas existências não se amoldam aos parâmetros legalmente estipulados. Por fim, serão realizadas algumas reflexões críticas quanto à necessidade de flexibilização de tais fronteiras e as possibilidades jurídicas para tanto.

\section{A noção de identidade para o direito}

O direito dedica-se a regular a vida em sociedade e, para tanto, além de estabelecer limites para condutas, promove a individualização de cada pessoa, a partir de critérios e características delimitadoras da identidade. É a partir do registro que o indivíduo existe formalmente, sendo-lhe atribuído um nome (prenome) que tem caráter definitivo, admitindose a alteração somente em casos especiais e previstos em lei (no caso, a Lei dos Registros Públicos - Lei 6.015/1973). A segurança jurídica é uma das principais razões para o estabelecimento de uma identidade fixa e imutável, classificada de acordo com os elementos previstos na $1 \mathrm{ei}^{1}$, desde o nascimento, podendo ser atualizada sempre que houver mudança no estado da pessoa.

\footnotetext{
${ }^{1}$ O artigo 54 da Lei de Registros Públicos estabelece os elementos necessários para o assento do registro do nascimento: “Art. 54. O assento do nascimento deverá conter: $1^{\circ}$ ) o dia, mês, ano e lugar do nascimento e a hora certa, sendo possível determiná-la, ou aproximada; $2^{\circ}$ ) o sexo do registrando; $3^{\circ}$ ) o fato de ser gêmeo, quando assim tiver acontecido; $4^{\circ}$ ) o nome e o prenome, que forem postos à criança; $5^{\circ}$ ) a declaração de que nasceu morta, ou morreu no ato ou logo depois do parto; $6^{\circ}$ ) a ordem de filiação de outros irmãos do mesmo prenome que existirem ou tiverem existido; $7^{\circ}$ ) Os nomes e prenomes, a naturalidade, a profissão dos pais, o lugar e cartório onde se casaram, a idade da genitora, do registrando em anos completos, na ocasião do parto, e o domicílio ou a residência do casal. $8^{\circ}$ ) os nomes e prenomes dos avós paternos e maternos; 9o) os nomes e prenomes, a profissão e a residência das duas testemunhas do assento, quando se tratar de parto ocorrido sem 
No entanto, quase que ironicamente e em completo desacordo com a segurança almejada pela visão cartesiana do direito, as identidades nada têm de fixas e imutáveis. São fluídas, mutáveis e instáveis, não seguindo a visão essencialista do direito. São identidades, no plural, "algumas vezes contraditórias ou não resolvidas" (HALL, 2006, p. 11).

Considera-se essencialista a percepção da identidade a partir de características compartilhadas e que não se alteram ao longo do tempo, como ocorre com o estabelecimento da identidade civil:

Com frequência, a identidade envolve reivindicações essencialistas sobre quem pertence e quem não pertence a um determinado grupo identitário, nas quais a identidade é vista como algo fixo e imutável. [...] O essencialismo pode fundamentar suas afirmações tanto na história quanto na biologia; por exemplo, certos movimentos políticos podem buscar alguma certeza na afirmação da identidade apelando seja à "verdade" fixa de um passado partilhado seja a "verdades" biológicas. O corpo é um dos locais envolvidos no estabelecimento das fronteiras que definem quem nós somos, servindo de fundamento para a identidade - por exemplo, para a identidade sexual (WOODWARD, 2014, p. 14-15).

Assim, a manutenção da lógica categorial moderna ${ }^{2}$ da identidade implica a insuficiência da tutela jurídica quanto à diversidade de manifestações das identidades humanas nos mais diversos âmbitos. Especialmente quanto ao gênero, a tutela da identidade a partir de uma perspectiva binária reforça a delimitação de fronteiras e evidencia a precariedade da concepção jurídica da identidade fixa.

A temática de gênero é, constantemente, objeto de discussões jurídicas. A título exemplificativo, citam-se inserções e modificações legislativas no tocante à proteção e prevenção de violência decorrente do gênero, como a promulgação da Lei Maria da Penha (Lei 11.340/2006) contra violência doméstica e a tipificação do feminicídio como qualificadora do crime de homicídio (Lei 13.104/2015). Também, o reconhecimento da união estável homoafetiva pelo Supremo Tribunal Federal em 2011, a partir do julgamento da ADPF 132 e ADI 4277 e a regulamentação do casamento civil entre pessoas do mesmo sexo pelo Conselho Nacional de Justiça (Resolução 175/2013).

Especificamente quanto à identidade, a questão que tem sido mais amplamente divulgada diz respeito à alteração de nome e sexo no registro civil daqueles indivíduos cuja identidade de gênero não condiz com o sexo biológico. Insta ressaltar que esse debate perpassa o campo da medicina, porquanto persiste o entendimento de que tal incompatibilidade configura um transtorno psicológico, mesmo após tal designação ter sido

assistência médica em residência ou fora de unidade hospitalar ou casa de saúde; 10) o número de identificação da Declaração de Nascido Vivo, com controle do dígito verificador, exceto na hipótese de registro tardio previsto no art. 46 desta Lei; e 11) a naturalidade do registrando". (BRASIL, 1973, grifo nosso).

2 Termo utilizado por María Lugones (2008), que será abordado com maior profundidade no segundo capítulo. 
afastada pela Organização Mundial da Saúde, a perspectiva patologizante ainda está presente no discurso jurídico.

O Supremo Tribunal Federal julgou procedente a Ação Direta de Inconstitucionalidade n. 4.275, a fim de dar interpretação conforme a Constituição e o Pacto de São José da Costa Rica ao art. 58 da Lei 6.015/73 (Lei de Registros Públicos), reconhecendo aos indivíduos transgêneros que assim o desejarem, independentemente da cirurgia de transgenitalização ou da realização de tratamentos hormonais, o direito à substituição de prenome e sexo diretamente no registro civil ${ }^{3}$. Em cumprimento à decisão, o Conselho Nacional de Justiça - CNJ editou o Provimento 73, estabelecendo regras a serem observadas pelos Cartórios de Registro Civil para alteração do prenome e sexo, mediante requerimento. Ainda, no julgamento da Repercussão Geral n. 670.422, o plenário aplicou o entendimento da ADI 4275, fixando a seguinte tese:

1 - O transgênero tem direito fundamental subjetivo à alteração de seu prenome e de sua classificação de gênero no registro civil, não se exigindo para tanto nada além da manifestação de vontade do indivíduo, o qual poderá exercer tal faculdade tanto pela via judicial como diretamente pela via administrativa.

2 - Essa alteração deve ser averbada à margem do assento de nascimento, vedada a inclusão do termo "transgênero".

3 - Nas certidões do registro não constará nenhuma observação sobre a origem do ato, vedada a expedição de certidão de inteiro teor, salvo a requerimento do próprio interessado ou por determinação judicial.

4 - Efetuando-se o procedimento pela via judicial, caberá ao magistrado determinar, de ofício ou a requerimento do interessado, a expedição de mandados específicos para a alteração dos demais registros nos órgãos públicos ou privados pertinentes, os quais deverão preservar o sigilo sobre a origem dos atos.

BRASIL. Supremo Tribunal Federal - STF. RECURSO EXTRAORDINÁRIO 670.422/RS. Relator: Ministro Dias Toffoli. Plenário, 15.8.2018, DJE n ${ }^{\circ} 42$, de 05 de março de 2018. DJE n 169, divulgado em 17/08/2018.

Tratando-se da tutela da identidade, existe uma diversidade de situações que exigem respostas do direito, como algumas questões envolvendo a previsão de uso do nome social por órgãos públicos e o tratamento social de acordo com a identidade de gênero, como a situação enfrentada no Recurso Extraordinário $845.779 / \mathrm{SC}^{4}$, que levou à Corte Constitucional o debate

\footnotetext{
${ }^{3}$ BRASIL. Supremo Tribunal Federal - STF. AÇÃO DIRETA DE INCONSTITUCIONALIDADE 4275. Redator para o Acórdão: Ministro Edson Fachin, Distrito Federal, 01 de março de 2018, DJE nº 42, de 05 de março de 2018.

${ }^{4}$ Em 13 de novembro de 2014, o Supremo Tribunal Federal reconheceu a repercussão geral da questão suscitada no RE 845.779, conforme a ementa a seguir transcrita: TRANSEXUAL. PROIBIÇÃO DE USO DE BANHEIRO FEMININO EM SHOPPING CENTER. ALEGADA VIOLAÇÃO À DIGNIDADE DA PESSOA HUMANA E A DIREITOS DA PERSONALIDADE. PRESENÇA DE REPERCUSSÃO GERAL. 1. O recurso busca discutir o enquadramento jurídico de fatos incontroversos: afastamento da Súmula 279/STF. Precedentes. 2. Constitui questão constitucional saber se uma pessoa pode ou não ser tratada socialmente como se pertencesse a sexo diverso do qual se identifica e se apresenta publicamente, pois a identidade sexual está diretamente ligada à dignidade da pessoa humana e a direitos da personalidade 3 . Repercussão geral configurada, por envolver discussão sobre o alcance de direitos fundamentais de minorias - uma das missões 
quanto à utilização de banheiro por pessoa transexual, a partir de ação indenizatória proposta em face de um shopping que impediu a utilização de banheiro de acordo com a identidade de gênero.

Além dessas, podem-se citar outras tantas situações cotidianas, que envolvem atividades comuns, mas que para indivíduos fora dos parâmetros impostos pela heteronormatividade $^{5}$ provocam constantes ofensas à dignidade, como a obrigatória consignação do sexo biológico no registro civil da pessoa natural e previsões de prazos diversos para licença maternidade e paternidade, entre outras.

Mais recentemente, o Supremo Tribunal Federal também foi protagonista de mais um importante passo para a proteção dos direitos de pessoas LGBTI. No julgamento da Ação Direta de Inconstitucionalidade por Omissão (ADO) n. 26, reconheceu a omissão legislativa no tocante à proteção penal da população LGBTI, dando interpretação conforme a Constituição ao tipo penal de racismo (Lei 7.716/89) a fim de enquadrar as práticas homotransfóbicas como prática de racismo, na dimensão de racismo social, fixando a seguinte tese:

1. Até que sobrevenha lei emanada do Congresso Nacional destinada a implementar os mandados de criminalização definidos nos incisos XLI e XLII do art. $5^{\circ}$ da Constituição da República, as condutas homofóbicas e transfóbicas, reais ou supostas, que envolvem aversão odiosa à orientação sexual ou à identidade de gênero de alguém, por traduzirem expressões de racismo, compreendido este em sua dimensão social, ajustam-se, por identidade de razão e mediante adequação típica, aos preceitos primários de incriminação definidos na Lei no 7.716 , de 08/01/1989, constituindo, também, na hipótese de homicídio doloso, circunstância que o qualifica, por configurar motivo torpe (Código Penal, art. 121, § 2 , I, "in fine");

2. A repressão penal à prática da homotransfobia não alcança nem restringe ou limita o exercício da liberdade religiosa, qualquer que seja a denominação confessional professada, a cujos fiéis e ministros (sacerdotes, pastores, rabinos, mulás ou clérigos muçulmanos e líderes ou celebrantes das religiões afro-brasileiras, entre outros) é assegurado o direito de pregar e de divulgar, livremente, pela palavra, pela imagem ou por qualquer outro meio, o seu pensamento e de externar suas convicções de acordo com o que se contiver em seus livros e códigos sagrados, bem assim o de ensinar segundo sua orientação doutrinária e/ou teológica, podendo buscar e conquistar prosélitos e praticar os atos de culto e respectiva liturgia, independentemente do espaço, público ou privado, de sua atuação individual ou coletiva, desde que tais manifestações não configurem discurso de ódio, assim entendidas aquelas exteriorizações que incitem a discriminação, a hostilidade ou a

precípuas das Cortes Constitucionais contemporâneas -, bem como por não se tratar de caso isolado. (BRASIL. Supremo Tribunal Federal - STF. REPERCUSSÃO GERAL NO RECURSO EXTRAORDINÁRIO 845.779 SANTA CATARINA. Relator: Ministro Roberto Barroso, Distrito Federal, 14 de novembro de 2014, DJE n 45 , publicado em 10/03/2015, grifo nosso).

5 Entende-se heteronormatividade a partir da genealogia foucaultiana, que demonstra formação do poder entendendo a heterossexualidade apresentar-se como norma, regulando a base de inteligibilidade cultural através da qual se naturaliza corpos/gêneros/desejos e definindo o modelo hegemônico de inteligibilidade de gênero, que supõe que para o corpo ter coerência e sentido deve haver um sexo estável expresso mediante o gênero estável ("masculino" expressa homem, "feminino" expressa mulher). A reprodução do dispositivo da sexualidade permite cultivar os corpos em com aparências "naturais" e disposições heterossexuais naturais. (BENTO, 2008). 
violência contra pessoas em razão de sua orientação sexual ou de sua identidade de gênero;

3. O conceito de racismo, compreendido em sua dimensão social, projeta-se para além de aspectos estritamente biológicos ou fenotípicos, pois resulta, enquanto manifestação de poder, de uma construção de índole histórico-cultural motivada pelo objetivo de justificar a desigualdade e destinada ao controle ideológico, à dominação política, à subjugação social e à negação da alteridade, da dignidade e da humanidade daqueles que, por integrarem grupo vulnerável (LGBTI+) e por não pertencerem ao estamento que detém posição de hegemonia em uma dada estrutura social, são considerados estranhos e diferentes, degradados à condição de marginais do ordenamento jurídico, expostos, em consequência de odiosa inferiorização e de perversa estigmatização, a uma injusta e lesiva situação de exclusão do sistema geral de proteção do direito, vencido o Ministro Marco Aurélio, que não subscreveu a tese proposta. BRASIL. Supremo Tribunal Federal - STF. AÇÃO DIRETA DE INCONSTITUCIONALIDADE POR OMISSÃO n. 26. Relator: Ministro Celso de Mello. Plenário, 13.06.2019. DJE nº 142, divulgado em 28/06/2019, grifo nosso.

Em que pese essa tendência de reconhecimento da diversidade e proteção das vulnerabilidades que pode ser observada no Judiciário, não se estende à sociedade brasileira como um todo. Destaca-se que, de acordo com a pesquisa "Trans Murder Monitoring", da ONG Transgender Europe, o Brasil lidera o ranking mundial de países que mais assassinam a população trans e de gênero diverso, tendo registrado, no período de $1^{\circ}$ de outubro de 2016 a 30 de setembro de 2017, um total de 171 casos (TRANSGENDER EUROPE, 2017).

Em 2019, segundo dados do Grupo Gay da Bahia, até 15 de maio, haviam sido registradas 141 mortes de pessoas lésbicas, gays, bissexuais e travestis, transgêneros e transexuais (GOMES, 2019).

Inexistem dados oficiais atuais do Governo brasileiro sobre o tema. Em análise no site do Ministério da Família, da Mulher e dos Direitos Humanos, as páginas relacionadas à temática LGBT possuem poucas informações ou não são mais divulgadas ${ }^{6}$.

Tal realidade pode ser também observada na representação política. Até recentemente, alguns projetos de lei estavam em tramitação no Congresso Nacional com o fito de regulamentar a alteração do prenome e sexo registrais, buscando adequá-los à "identidade de gênero". Todavia, seus conteúdos estão longe da aprovação e tendem a sofrer profundas modificações ou serem integralmente rejeitados, a considerar a forte tendência ao conservadorismo que o poder legislativo federal apresenta. Algumas proposições perante a Câmara dos Deputados $^{7}$ e o Senado Federal $^{8}$ tiveram a tramitação encerrada pelo fim da legislatura em 2018.

\footnotetext{
${ }^{6}$ Análise do site https://www.mdh.gov.br/navegue-por-temas/lgbt em 25/03/2020. Na página de relatórios, inexistem documentos, apenas menção a dados de 2017. Não há acesso ao item "Ações e programas". As últimas notícias são de abril de 2019.

${ }^{7}$ Exemplificando, na Câmara dos Deputados encontravam-se em tramitação, alguns projetos de lei relacionados à temática de gênero e identidade, como o Projeto de Lei no 5002/2013, denominado de Projeto da Lei João W. 
A percepção quanto ao conservadorismo decorre do posicionamento apresentados por bancadas der parlamentares relacionados a fundamentalismos religioso, militar e ruralista, cujas atuações podem ser observadas pela apresentação de projetos de lei buscando a restrição da liberdade sexual, bem como a desconstrução de garantias relativamente consolidadas, como o uso do nome social. Nesse sentido, citam-se, a título exemplificativo, alguns projetos de lei apresentados pelos Deputados Federais:

a) o PL 8.614/2017, que visa proibir a inserção de nome social em documentos oficiais, apensado ao PL 8.174/2017, com mesmo objetivo, que encontra-se arquivado ante o encerramento da legislatura.

b) as diversas manifestações contra a chamada "ideologia de gênero", buscando restringir discussões relativas a gênero e a sexualidade em escolas, como no caso do Projeto de Lei 867 de 2015, que trata do "Programa Escola sem Partido".

O projeto foi apensado ao PL 7180/2014, que segue em tramitação buscando alterar a Lei de Diretrizes e Bases da Educação Nacional (Lei 9.394/96) a fim de incluir dentre os princípios do ensino o seguinte:

XIII - respeito às convicções do aluno, de seus pais ou responsáveis, tendo os valores de ordem familiar precedência sobre a educação escolar nos aspectos relacionados à educação moral, sexual e religiosa, vedada a transversalidade ou técnicas subliminares no ensino desses temas.

Neste ponto, cabe destacar que em âmbito estadual e municipal já foram aprovadas diversas restrições, temática que foi objetivo da Audiência Pública realizada no $162^{\circ}$ Período de Sessões da Comissão Interamericana de Direitos Humanos com a Temática: "Direitos humanos e educação livre, plural e sem censura no Brasil: a proposta de exclusão da perspectiva de identidade de gênero e orientação sexual na Base Curricular Comum Nacional e o projeto "Escola Sem Partido"'.

\footnotetext{
Nery ou Lei de Identidade de Gênero trata da alteração do nome e gênero no registro civil de pessoa transexual, arquivado em 31/01/2019. Em sentido similar, o Projeto de lei $\mathrm{n}^{\circ} 4.241 / 12$ versa sobre direito à identidade de gênero, atualmente apensado ao Projeto de Lei no 70/1995 que dispõe sobre intervenções cirúrgicas para alteração de sexo, cuja última movimentação ocorreu em 01/11/2012. Também existem alguns projetos que tratam mais especificamente dos direitos de pessoas intersexuais, dispondo sobre a suspensão da exigência de declaração do sexo/gênero no registro de nascimento de crianças intersexuais, bem como de alterações no documento de identificação civil, a fim de suprimir a indicação de sexo, os Projetos de Lei no 5.255 e 5.453 de 2016 e o Projeto de Lei $n^{\circ} 1.475$ de 2015. Estes também foram apensados ao Projeto de Lei $n^{\circ} 4241$ de 2012 e, consequentemente, ao Projeto de 1995, acima citado, que adota uma visão extremamente medicalizada da questão, além de demonstrar o tratamento genérico, atécnico e pouco aprofundado dessas temáticas pelos legisladores.

8 No Senado Federal, encontrava-se em tramitação o PLS 658/2011, de autoria da Senadora Marta Suplicy (PT/SP), que também foi arquivado em razão do final da legislatura, em 03/01/19.

${ }^{9}$ Disponível em: < http://cevige.com.br/memorial-audiencia-publica-cidh-162-periodo-de-sessoes/>. 
As diversas manifestações contra a chamada "ideologia de gênero" buscando restringir discussões relativas a gênero e a sexualidade em escolas, como parte de uma agenda profundamente conservadora, em consonância aos posicionamento das bancadas parlamentares relacionados a fundamentalismos religioso, militar e ruralista, com atuação na apresentação de projetos de lei buscando a restrição da liberdade sexual e a desconstrução de garantias consolidadas, como o uso do nome social. A este respeito, insta destacar a recente decisão proferida pelo Supremo Tribunal Federal na Arguição de Descumprimento de Preceito Fundamental (ADPF) 457, que reconheceu, por unanimidade, a inconstitucionalidade de lei do município de Nova Gama (GO) inspirada no Movimento Escola Sem Partido.

c) o PL 2596/2019, que “estabelece o sexo biológico como único critério para definição do gênero em competições esportivas oficiais no território brasileiro", apensado ao PL 2200/19, que “dispõe sobre a proibição da participação de atletas transexuais do sexo masculino (HOMENS TRAVESTIDOS OU FANTASIADOS DE MULHER) em competições do sexo feminino em todo o Território Nacional”, que aguarda parecer do Relator na Comissão de Direitos Humanos e Minorias (CDHM).

d) o PL 477/2015 que objetivava afastar a aplicação da legislação que coíbe a violência doméstica em relação à população trans, alterando-se a palavra "gênero" por "sexo" nas previsões da Lei Maria da Penha, assim justificando a proposta:

[...] o conceito [gênero] está sendo utilizado para promover uma revolução cultural sexual de orientação neo-marxista. Na submissão do feminino ao masculino através da família, Marx e Engels enxergaram o protótipo de todos os subsequentes sistemas de poder. Se esta submissão é consequência da biologia, não há nada a que se fazer. Mas se ela é uma construção social, ou um gênero, então, a longo prazo, ela poderia ser modificada até chegar-se à uma completa igualdade onde não haveria mais possibilidade de opressão de gênero, mas também em que não haveria mais famílias, tanto heterossexuais como alternativas, em que a educação caberia como uma tarefa exclusiva do Estado, e onde não existiria nenhum traço diferencial entre o masculino e o feminino. Em um mundo de genuína igualdade, segundo esta concepção, todos teriam que ser educados como bissexuais e a masculinidade e a feminilidade deixariam de ser naturais. A curto prazo, a substituição da luta contra a discriminação da mulher pela luta contra a discriminação de gênero desvirtua o foco pela luta a favor da mulher" (BRASIL, CÂMARA DOS DEPUTADOS, 2015).

Salienta-se que o autor requereu a retirada de tramitação do Projeto em 11 de agosto de 2016, sem apontar razões para o pedido.

Diferente da percepção majoritária nas casas legislativas, a doutrina jurídica brasileira reconhece que a sexualidade integra a condição humana, devendo ser respeitada pela sociedade, a fim de que o sujeito se realize como ser humano:

Indispensável que se reconheça que a sexualidade integra a própria condição humana. Ninguém pode realizar-se como ser humano se não tiver assegurado o 
respeito ao exercício da sua sexualidade, conceito que compreende tanto a liberdade sexual como a liberdade à livre orientação sexual. A sexualidade é um elemento da própria natureza humana, seja individualmente, seja genericamente considerada. Sem liberdade sexual, sem direito ao livre exercício de sua sexualidade, sem opção sexual livre, o próprio gênero humano não consegue alcançar a felicidade, falta-lhe a liberdade, que é um direito fundamental (DIAS, 2006, p. 73).

Diante autonomia da pessoa em gerir sua vida e relações, a doutrina civilista brasileira, de maneira geral, associa à tutela dos direitos da personalidade os relacionados à vida e à integridade física, psíquica e moral do indivíduo, o nome, a imagem, a honra e a intimidade. A temática dos direitos da personalidade refere-se, assim, ao espaço de proteção jurídica da própria existência humana. Dentre tais direitos, destaca-se o direito à identidade, composto, dentre outros aspectos, pela proteção do corpo, do nome e da intimidade.

Com norte nessas reflexões, evidencia-se a necessidade de um repensar da tutela jurídica da identidade do sujeito humano, a partir de uma leitura não binária, ancorada na noção de autonomia da pessoa e de sua dignidade. Nesse sentido, a revisão da noção jurídica de sujeito e de identidade é necessária para possibilitar a abertura das fronteiras fixadas pelo direito e, consequentemente, abranger os indivíduos que tem sua existência jurídica restringida.

\section{Sujeito(s) e Identidade(s): Flexionar fronteiras, reconhecer humanidade}

A noção de sujeito uno, própria do Iluminismo, que via surgir do indivíduo a sua identidade, clara e imutável, que o acompanharia pela vida toda, foi, progressivamente, substituída por uma visão sociológica, refletora da complexidade das relações modernas. A constatação que o núcleo interior do sujeito não era autônomo e autossuficiente modificou a concepção de identidade, ao reconhecer que as relações interpessoais e a relação entre sujeito e sociedade também influenciavam na formação da identidade:

\footnotetext{
O sujeito, previamente vivido como tendo identidade unificada e estável, está se tornando fragmentado; composto não de uma única, mas de várias identidades, algumas vezes contraditórias ou não-resolvidas. Correspondentemente, as identidades, que compunham as paisagens sociais "lá fora" e que asseguravam nossa conformidade subjetiva com as "necessidades" objetivas da cultura, estão entrando em colapso, como resultado de mudanças estruturais e institucionais. O próprio processo de identificação, através do qual nos projetamos em nossas identidades culturais, tornou-se mais provisório, variável e problemático (HALL, 2006, p. 12).
}

Trata-se de uma visão pós-moderna do sujeito, que pode ser observada nas obras de Judith Butler. A filósofa norte-americana dedica-se à reflexão acerca da identidade e da subjetividade, descrevendo os processos de formação dos sujeitos dentro das estruturas de 
poder existentes na sociedade. Para ela, o sujeito está em constante formação, "envolvido num processo de devir sem fim" (SALIH, 2017, p. 10-11). Desse modo, adota-se a visão das identidades não a partir da rigidez binária, mas a partir de um viés que "embora seja construído por meio da diferença, o significado não é fixo" e sim diferido ou adiado, conforme o conceito de différance (Derrida), enfatizando sua fluidez (WOODWARD, 2014, p. 29).

Entender que as identidades não são unificáveis permite demonstrar que o sujeito pós-moderno, na formação das suas identidades enfrenta suas contradições internas: em determinadas situações assume determinadas identidades e em outros momentos, identidades diferentes (HALL, 2006). Diante desse caráter relacional da identidade, a diferença é estabelecida a partir de uma marcação simbólica, o que também contribui para a criação de sistemas classificatórios, fixados a partir de modelos de divisão e organização social, formadores de grupos em oposição, como o "nós" e o "eles".

Nesse sentido, a formação das identidades nada tem de simples, sofrendo influências de diversos aspectos culturais e sociais. Ou seja, a "identidade é marcada pela diferença, mas parece que algumas diferenças [...] são vistas como mais importantes que outras, especialmente em lugares particulares e momentos particulares" (WOODWARD, 2014, p. 11). Quanto às diferenças, adota-se a noção de fronteiras como a forma pela qual os sujeitos são categorizados, unindo os iguais e destacando os diferentes.

São várias as categorias delimitadoras de fronteiras entre as identidades e, consequentemente, entre os sujeitos e não-sujeitos. Historicamente, o corpo, entendido como uma unidade orgânica, autonomamente integrada, superfície passiva e fixa, uma realidade pré-discursiva, de determinação essencialmente biológica, serviu de fundamento para a identidade em diversos aspectos, como a raça, a sexualidade e o gênero.

A lógica categorial moderna foi culturalmente criada e imposta a partir de fundamentos supostamente biológicos, como explica María Lugones (2008), que compreende a separação categorial como uma separação forçada de categorias inseparáveis, fundamentando a distinção baseada na imposição e em relações de dominação perpetuadas cultural e socialmente. Assim, compreender os recursos historicamente específicos de organização do gênero no sistema moderno/colonial de gênero (dimorfismo biológico, organização patriarcal e heterossexual das relações sociais) é central para uma compreensão da organização diferencial de gênero e as lógicas de superioridade e inferioridade estabelecidas na dominação e perpetuadas pelas relações de poder. Trata-se da criação e imposição de fronteiras que, com a expansão colonial europeia, difundiram-se sobre o planeta 
permeando todas as áreas da existência social e tornando-se a forma mais eficaz de dominação social, material e intersubjetiva (LUGONES, 2008, p. 79).

As identidades decorrem também das relações interpessoais, as quais possuem componentes de poder e hierarquia (homens versus mulheres; pais versus filhos; brancos versus negros; patrões versus operários). A partir de uma leitura foucaultiana, o poder é exercido a partir de inúmeros pontos, em meio a relações heterogêneas e instáveis, articulado com discursos e saberes. Nesse sentido, o direito é responsável pela fixação de identidades pré-concebidas e imutáveis, sob pena de se fugir do padrão de normalidade.

Porém, “onde há poder há resistência” (FOUCAULT, 2010). Dentre os mecanismos de resistência, os movimentos sociais exercem papel relevante. O movimento feminista busca superar essas formas tradicionais de organização, permeadas pela assimetria e pelo autoritarismo, discute a relação de poder entre os sexos, demonstrando que ela é baseada muito mais em critérios sociais que biológicos:

O masculino e o feminino são criações culturais e, como tal, são comportamentos
apreendidos através do processo de socialização que condiciona diferentemente os
sexos para cumprirem funções sociais específicas e diversas. Essa aprendizagem é
um processo social: "aprende-se" a ser homem e mulher e a aceitar como naturais as
relações de poder entre os sexos. A menina aprende a ser doce, obediente, passiva,
dependente, enquanto que o menino aprende a ser agressivo, competitivo, ativo,
independente, como se tais qualidades fossem parte de sua natureza. Esse
reducionismo biológico camufla as verdadeiras raízes da opressão da mulher, que é
fruto de relações sociais (RODRIGUES; GADENZ; LA RUE, 2014, p. 6).

A compreensão das diferenças sociais entre o masculino e o feminino como decorrência apenas da diferença biológica permeia o corpo social, naturaliza também o gênero (a performatividade do corpo masculino e do corpo feminino), que é, em verdade, uma construção natural, dogmática, arbitrária, culturalmente independente e, portanto, a-histórica. Assim, o gênero é um meio discursivo que estabelece ao sexo como algo natural e anterior à cultura, criando a ficção de uma assepsia política (MARTINEZ, 2015, p. 8).

Butler questiona a predeterminação dos sujeitos a partir das imposições biológicas (lógica categorial moderna, para Lugones), desconstrói as categorias e demonstra a indeterminação e a instabilidade de todas as identidades sexuadas e generificadas. Em sua leitura, assim como o gênero, o sexo também é uma construção cultural e social e, portanto, não pode ser imposto por características biológicas. Dessa forma, a relação entre sexo e gênero é construída politicamente:

A matriz cultural por meio da qual a identidade de gênero se torna inteligível exige que certos tipos de "identidade" não possam "existir" - isto é, aqueles em que o gênero não decorre do sexo e aqueles em que as práticas do desejo não "decorrem" 
nem do "sexo" nem do "gênero". Nesse contexto, "decorrer" seria uma relação política de direito instituído pelas leis culturais que estabelecem e regulam a forma e o significado da sexualidade. Ora, do ponto de vista desse campo, certos tipos de "identidade de gênero" parecem ser meras falhas do desenvolvimento ou impossibilidades lógicas, precisamente por não se conformarem às normas de inteligibilidade cultural. Entretanto, sua persistência e proliferação criam oportunidades críticas de expor os limites e os objetivos reguladores desse campo de inteligibilidade, matrizes rivais e subversivas de desordem do gênero (BUTLER, 2017a, p. 44).

A filósofa não vê o gênero como extensão conceitual ou cultural do sexo cromossômico, mas uma prática discursiva (numa compreensão influenciada de Foucault) centrada na heterossexualidade como norma das relações humanas. É essa heterossexualidade compulsória que provoca uma "falsa coerência entre gêneros aparentemente estáveis ligados aos sexos biológicos adequados" (SPARGO, 2017, p. 42).

Tal determinismo biológico fundamenta a lógica categorial moderna que regula a identidade, incorporando explicações que dão conta da construção social com base em concepções culturalmente construídas que leem o corpo como base natural e neutra. Assim, a categoria supostamente biológica sexo constituiu a referência inquestionável da identidade com base no dimorfismo que impõe aos corpos e funciona como inibidor de possibilidades ao gênero, também categoria de referência identitária (MARTINEZ, 2015, p. 3).

$\mathrm{O}$ direito utiliza dessa mesma lógica para regular a vida dos indivíduos. $\mathrm{O}$ discurso da sexologia produziu as categorias identitárias e todo seu vocabulário. Assim, incita-se um discurso de reação, em que a afirmação positiva da identidade surge como resposta a um discurso pejorativo e opressor. Esse discurso é a base para a teoria queer ${ }^{10}$.

Assim, considerando que o ordenamento jurídico brasileiro tem na dignidade da pessoa humana uma cláusula geral de tutela e promoção da pessoa humana, os direitos de personalidade correspondem aos direitos subjetivos garantidos a toda e qualquer pessoa, alcançando sua integridade física, intelectual e moral, de modo a concretizar sua personalidade, em si própria e em relação à sociedade. Ou seja, os direitos da personalidade são inerentes à pessoa e à sua dignidade, essenciais para a proteção da própria identidade da pessoa em si mesma e perante a sociedade (TEPEDINO, 2004, p. 50). Nesse âmbito,

\footnotetext{
${ }^{10} \mathrm{O}$ termo queer, originalmente vinculado à homofobia e ao preconceito, foi "apropriado" pelas estratégias de ativismo, a fim de descrever "uma gama diversificada de práticas e prioridades críticas: interpretações da representação do desejo entre pessoas do mesmo sexto em textos literários, filmes, músicas e imagens; análise das relações de poder sociais e políticas da sexualidade, críticas do sistema sexo-gênero; estudos sobre identificação transexual e transgênero, sobre sadomasoquismo e sobre desejos transgressivos". O movimento busca desvincular essa do estigma minoritário, buscando promover uma imagem positiva da identidade gay, permitindo também que aqueles "que achavam as identidades "gay" e "lésbica" inadequadas ou restritivas, acharam no termo gay uma posição com a qual se identificar". Destaca que, "em teoria, queer está incessantemente em desacordo com o normal, a norma, seja a heterossexualidade dominante ou a identidade gay/lésbica. É categoricamente excêntrico, a-normal”. (SPARGO, 2017, p. 32-33.)
} 
questionar a fixação da identidade e a exclusão das identidades destoantes é fundamental para garantir o livre desenvolvimento das personalidades humanas, como concretização de sua dignidade.

No capítulo seguinte, serão feitas algumas reflexões, a partir do viés constitucionalizado do direito civil, acerca da insuficiência do modelo atual de regulação identitária.

\section{A reformulação jurídica das identidades: reflexões necessárias}

Como visto, as identidades, que pouco têm de estáveis, pois permeadas por fluidez, são "emolduradas" por critérios rígidos, buscando categorizar o indivíduo, reduzindo ao máximo a expressão e exteriorização de características incompatíveis com o padrão de normalidade criado e mantido com o apoio do direito. Isso provoca a exclusão das pessoas cujas identidades não condizem com os modelos pré-determinados, renegando-os à condição de não-sujeitos, ou seja, vidas que não importam ${ }^{11}$.

O "gênero" foi, ao longo dos séculos, social e juridicamente reforçado como delimitador de identidade, contribuindo para a perpetuação de crenças epistemológicas próprias da modernidade, divisões sociais baseadas na dicotomia masculino/feminino e suas derivações (subjetividade/ciência, lógica/imaginação, razão/paixão, ciência/arte, realidade/invenção) (COSTA, 2011, p. 168). Reflexo dessa lógica, a insuficiência da tutela jurídica quanto à diversidade de manifestações da(s) identidade(s) é evidente.

Nesse sentido, pode-se afirmar que o modelo atual, ao tratar da formação e tutela da identidade a partir da perspectiva binária de gênero reforça a delimitação de fronteiras,

\footnotetext{
${ }^{11}$ Refere-se aqui à obra de Judith Butler, Quadros de Guerra: quando a vida é passível de luto? (Frames of War) na qual a autora provoca a reflexão sobre as vidas que são desconsideradas, aqueles que "não importam". A obra aborda as diversas formas de violência que permeiam as relações contemporâneas e, a partir delas, explica as diferenças entre as vidas que são consideradas passíveis de luto daquelas consideradas indignas de serem vividas e, portanto, não reconhecidas como vidas. A autora utiliza a noção de precariedade para demonstrar como tais enquadramentos são construídos e perpetuados na sociedade, a partir de discursos opressores das pessoas consideradas minoria, seja ela racial, étnica, econômica, política ou social. Segundo Butler, a diferença na resposta afetiva e valoração moral decorre dos enquadramentos que fazem com que certas vidas sejam consideradas dignas de proteção e outras não, pois não são completamente "vidas". A partir da ideia de precariedade, a filósofa demonstra que o valor da vida apresenta-se nas condições em que ela pode ser perdida, assim, esclarece que não apenas vítimas de conflitos não são consideradas ou cujas vidas perdidas são aceitas em prol de um bem maior, mas todos os indivíduos que compõem grupos considerados outsiders, indignos ou repulsivos, fazendo com que todo o aparelho social funcione de modo a excluí-los e legitimar essa exclusão. A autora analisa a vida sobre uma ontologia social, que foge do antropocentrismo individualista: "A questão não é saber se determinado ser é vivo ou não, nem se ele tem o estatuto de "pessoa"; trata-se de saber, na verdade, se as condições sociais de sobrevivência e prosperidade são ou não possíveis". A vida, portanto, exige uma série de condições sociais e políticas que a possibilitem ser vivível, não bastando o mero impulso interno para viver (BUTLER, 2017b).
} 
evidencia a precariedade da visão jurídica da identidade, reflexo da matriz heteronormativa, e inviabiliza a existência jurídica da pessoa que se encontra fora dos limites culturalmente aceitos.

Sabidamente, a dignidade da pessoa humana deve nortear a atuação estatal no plano jurídico, pois é valor intrínseco da pessoa e consagrada nos mais diversos direitos fundamentais, em especial a proteção à vida e à igualdade. Significa dizer que "todas as pessoas têm o mesmo valor intrínseco e, portanto, merecem igual respeito e consideração, independente de raça, cor, sexo, religião, origem nacional ou social ou qualquer outra condição" e isso precisa ser materializado para a concretização da "dignidade individual (igualdade como reconhecimento)" (BARROSO, 2010).

Assim, o direito civil contemporâneo, lido a partir de uma perspectiva constitucionalizada e prospectiva (FACHIN, 2015), possui na funcionalização social um de seus alicerces. Neste ponto, ressalta-se a leitura de Ruzyk (2011), no sentido de que a função social do direito civil não deve ser relacionada a uma coletividade sem face ou a uma concepção abstrata de indivíduo, mas à liberdade da pessoa concretamente considerada em suas relações intersubjetivas e no livre desenvolvimento de sua personalidade, dando ênfase além do "social", atendendo a uma verdadeira "função reprodutora da pessoa". Tal concepção de função social tem por fundamento um conceito plural de liberdade, relacionado à dimensão existencial das pessoas, buscando proteger suas identidades próprias e assegurar a livre manifestação das subjetividades.

Nessa toada, defende-se uma leitura das identidades não binárias a partir da visão da liberdade existencial, ou seja, de que o sistema jurídico possibilite, efetivamente, a existência jurídica (e social) daqueles que não se enquadram no padrão da normalidade. Sabe-se que não se trata apenas de mera alteração de posicionamento jurisprudencial ou legislativo, mas de uma efetiva modificação cultural da sociedade.

Buscou-se demonstrar que o sistema jurídico perpetua a invisibilização dos sujeitos não-binários. $\mathrm{O}$ enfrentamento da visão moderna do direito e que ainda produz reflexos na tutela jurídica da identidade, a partir de uma visão prospectiva e constitucionalizada do direito civil, trata do livre desenvolvimento da personalidade, ou seja, trata da liberdade de existir. Segundo Louro, o desafio não é somente compreender a multiplicação das posições de gênero e sexuais, mas “que é impossível lidar com elas apoiadas em sistemas binários; mas também admitir que as fronteiras vêm sendo constantemente atravessadas e - o que é ainda mais complicado - que o lugar social no qual alguns sujeitos vivem é exatamente a fronteira" (LOURO, 2016, p. 28). 
Assim, considerando que a função social do direito civil não se relaciona a uma concepção abstrata de indivíduo, mas à liberdade da pessoa concretamente considerada em suas relações intersubjetivas, o abarcamento de um conceito plural de liberdade, relacionado à dimensão existencial das pessoas, é essencial para que sejam criadas soluções jurídicas efetivamente protetivas das identidades e promotoras do livre desenvolvimento da personalidade.

Busca-se um direito novo, liberto de mecanismos de normalização, resistente às disciplinas e aos dispositivos de segurança, uma forma de libertação da submissão dos indivíduos dos mecanismos de normalização:

\begin{abstract}
De fato, soberania e disciplina, legislação, direito da soberania e mecânicas disciplinares são duas peças absolutamente constitutivas dos mecanismos gerais de poder em nossa sociedade. Para dizer a verdade, para lutar contra as disciplinas, ou melhor, contra o poder, disciplinar, na busca de um poder não disciplinas, não é na direção do antigo direito da soberania que se deveria ir; seria antes em direção de um direito novo, que seria antidisciplinar, mas que estaria ao mesmo tempo liberto do princípio da soberania (FOUCAULT, 2010, p. 34-35).
\end{abstract}

Em outras palavras, trata-se de romper o enquadramento, de oferecer resistência à norma: "O que acontece quando um enquadramento rompe consigo mesmo é que uma realidade aceita sem discussão é colocada em xeque, expondo os planos orquestradores da autoridade que procurava controlar o enquadramento" (BUTLER, 2017b, p. 28).

Ciente do desafio que isso representa, não se pode deixar de ressaltar que o direito possui um importante papel de modificação social e cultural. Nesse sentido, a maturação da questão no campo do direito brasileiro é fundamental, o que somente será realizado a partir de uma reflexão crítica. Desse modo, o debate é essencial para o desenvolvimento de alternativas ao sistema atual que, além de estigmatizar a diferença, fomenta a exclusão dos sujeitos que daqueles que não se enquadram no padrão e violações aos seus direitos fundamentais e humanos.

\title{
5 Conclusão
}

A noção de "verdade" do sexo, exposta ironicamente por Foucault, representa como as práticas reguladoras reproduzidas pelas normas médicas e jurídicas ignoram as questões de gênero, reforçando ideais de identidade dentro de uma matriz que denote coerência entre sexo e gênero. Essa falsa coerência é responsável pela invisibilidade das questões a respeito das sexualidades humanas pelo direito, que reforça o status quo, sendo responsável pela 
manutenção da noção de identidades como pré-concebidas e imutáveis, promovendo a exclusão daqueles que se encontram foram da "normalidade".

A crítica apresentada busca demonstrar como as categorias de identidade tuteladas juridicamente são, na verdade, efeitos de instituições, práticas e discursos. Assim, a desconstrução da unidade do gênero, efeito de uma prática reguladora que busca uniformizar a identidade de gênero (heterossexualidade compulsória), é fundamental para permitir a interpretação e aplicação das normas jurídicas a partir de uma perspectiva libertadora capaz de, tanto no âmbito social quanto jurídico, reconhecer identidades emancipatórias, a fim de garanti-las autonomia e dignidade.

Com a exposição dos limites da regulação jurídica da identidade no direito brasileiro, buscou-se oferecer a essas aparentes desconformidades identitárias uma análise crítica demonstrativa da urgência em situar aqueles que se encontram fora das fronteiras delimitadas pela lógica categorial moderna da identidade, como sujeitos de direito merecedores da mesma proteção que é garantida a todos os cidadãos.

No entanto, mesmo diante de alguns avanços, verificou-se que o estigma identitário, fundado na (resistente) visão moderna do direito, ainda produz reflexos na tutela jurídica da identidade. Portanto, afirma-se a necessidade de, numa visão prospectiva e constitucionalizada da tutela jurídica da identidade, observar e promover o livre desenvolvimento da personalidade, ou seja, a liberdade de existir.

Nesse sentido, considerando que a função social do direito civil não se relaciona a uma concepção abstrata de indivíduo, mas à liberdade da pessoa concretamente considerada em suas relações intersubjetivas, entende-se que o abarcamento de um conceito plural de liberdade, relacionado à dimensão existencial das pessoas, permitirá soluções que efetivamente protejam suas identidades e promovam o livre desenvolvimento de sua personalidade.

\section{Referências}

BARROSO, Luís Roberto. A Dignidade da Pessoa Humana no Direito Constitucional Contemporâneo: Natureza Jurídica, Conteúdos Mínimos e Critérios de Aplicação. Versão provisória para debate público. Mimeografado, dezembro de 2010.

BENTO, Berenice Alves de Melo. O que é transexualidade. São Paulo: Brasiliense, 2008.

BRASIL. Câmara dos Deputados. Projeto de Lei no 5002 de 2013. Apresentado em 20/02/2013. Disponível em: 
$<$ http://www.camara.gov.br/proposicoesWeb/fichadetramitacao?idProposicao=56531 $>$. Acesso em: 23/03/2020

Câmara dos Deputados. Projeto de Lei no 477 de 2015. Autor: Deputado Eros Biondini - PTB/MG. Apresentado em 25/02/2015. Retirado em 12/08/2016. Disponível em: $<$ http://www.camara.gov.br/proposicoesWeb/fichadetramitacao?idProposicao=949119 $>$. Acesso em: 23/03/2020

Câmara dos Deputados. Projeto de Lei n⿳0 867 de 2015. Autor: Deputado Izalci PSDB/DF. Apresentado em 23/03/2015. Disponível em:

$<$ http://www.camara.gov.br/proposicoesWeb/fichadetramitacao?idProposicao=1050668 $>$. Acesso em: 23/03/2020

Câmara dos Deputados. Projeto de Lei n⿳0 8614 de 2017. Autor: Deputado Flavinho - PSB/SP. Apresentado em 19/09/2017. Disponível em:

$<$ http://www.camara.gov.br/proposicoesWeb/fichadetramitacao?idProposicao $=2152055>$. Acesso em 23/03/2020

BRASIL. Câmara dos Deputados. Projeto de Lei $\mathbf{n}^{\mathbf{0}}$ 2200/2019. Autor: Pastor Sargento Isidório - AVANTE/BA. Apresentado em 10/04/2019. Disponível em:

$<$ https://www.camara.leg.br/proposicoesWeb/fichadetramitacao?idProposicao=2197492\&ord $=1>$. Acesso em: 23/03/2020

Lei $\mathbf{n}^{0}$ 6.015, de 31 de dezembro de 1973. Dispõe sobre os registros públicos, e dá outras providências. Disponível em: $<$ http://www.planalto.gov.br/ccivil_03/leis/L6015compilada.htm>. Acesso em: 07 de julho de 2018.

Senado Federal. Projeto de Lei do Senado n⿳0 658, de 2011. Disponível em:

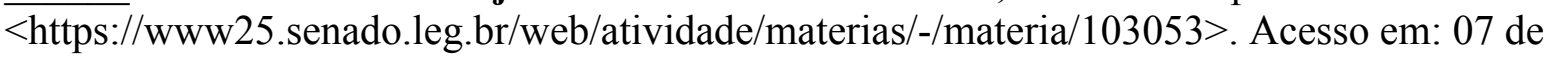
julho de 2018

Supremo Tribunal Federal - STF. REPERCUSSÃO GERAL NO RECURSO

EXTRAORDINÁRIO 845.779 SANTA CATARINA. Relator: Ministro Roberto Barroso, Distrito Federal, 14 de novembro de 2014, DJE nº 45, publicado em 10/03/2015

Supremo Tribunal Federal - STF. AÇÃO DIRETA DE

INCONSTITUCIONALIDADE 4275. Redator para o Acórdão: Ministro Edson Fachin, Distrito Federal, 01 de março de 2018, DJE n ${ }^{\circ}$ 42, de 05 de março de 2018

BUTLER, Judith. Problemas de gênero: feminismo e subversão da identidade. Tradução de Renato Aguiar. 13 ed. Rio de Janeiro: Editora Civilização Brasileira, 2017a.

Quadros de Guerra: Quando a vida é passível de luto? Tradução: Sérgio Tadeu de Niemeyer Lamarão e Arnaldo Marques da Cunha. 3.ed. Rio de Janeiro: Civilização Brasileira, $2017 b$.

COSTA, Pietro. Discurso jurídico e imaginação: hipóteses para uma antropologia do jurista. In: PETIT, Carlos (org.). Paixões do jurista: amor, memória, melancolia, imaginação.

Curitiba: Juruá, 2011. 
CRUZ, Daniel Nery da. A DISCUSSÃO FILOSÓFICA DA MODERNIDADE E DA PÓS -

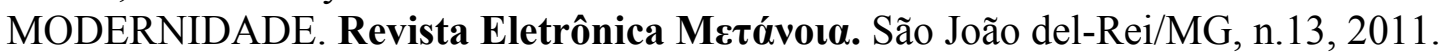

Disponível em: <http://www.ufsj.edu.br/portal2-

repositorio/File/revistalable/3_DANIEL_NERY_DA_CRUZ.pdf $>$. Acesso em 20 de maio de 2017.

DIAS, Maria Berenice. União Homossexual: O Preconceito \& A Justiça. 3. ed. Porto Alegre: Livraria do Advogado, 2006.

FACHIN, Luiz Edson. Direito Civil: sentidos, transformações e fim. Rio de Janeiro: Renovar, 2015.

FOUCAULT, Michel. Em defesa da sociedade: Curso no Còllege de France (1975-1976). Trad. Maria Ermantina Galvão. 2a ed. São Paulo: Editora WMF Martins Fontes, 2010.

História da Sexualidade I: A Vontade de Saber. Rio de Janeiro: Paz e Terra, 2017.

GOMES, Paulo. Ao menos uma pessoa é morta por dia no Brasil por homofobia, diz relatório. Folha de São Paulo. 17 mai, 2019. Disponível em:

$<$ https://www1.folha.uol.com.br/cotidiano/2019/05/ao-menos-uma-pessoa-e-morta-por-diano-brasil-por-homofobia-diz-relatorio.shtml>. Acesso em: 04 set. 2019.

HALL, Stuart. A identidade cultural na pós-modernidade. Tradução: Tomaz Tadeu da Silva e Guacira Lopes Louro. $11^{\mathrm{a}}$ ed. Rio de Janeiro: DP\&A, 2006.

LOURO, Guacira Lopes. Um corpo estranho: ensaios sobre a sexualidade e a teoria queer. 2. ed. Belo Horizonte: Autêntica, 2016.

LUGONES, M. Colonialidad y género. Tabula Rasa. n. 9. Bogotá, 2008, p. 73-101.

MARTÍNEZ, Ariel. APUNTES SOBRE EL CUERPO EN EL PENSAMIENTO DE JUDITH BUTLER. APORTES DEL PSICOANÁLISIS EN LA TEORÍA QUEER Revista Affectio Societatis, Vol. 12, No 23, Universidad de Antioquia. Medellín: julio-diciembre de 2015.

MATOS, Ana Carla Harmatiuk.; SANTOS, Andressa Regina Bissolotti dos. O DIREITO À EXISTENCIA CIVIL DE PESSOAS INTERSEXUAIS: UM QUESTIONAMENTO DO ESTATUTO JURÍDICO DO GÊNERO. In: DIAS, Maria Berenice (Coord). INTERSEXO. São Paulo: Revista dos Tribunais, 2018.

RODRIGUES, Alexandra Gato; GADENZ, Danielli; LA RUE, Letícia Almeida de. Feminismo.com: O movimento feminista na sociedade em rede. Derecho y Cambio Social. Peru, ISSN: 2224-4131, 2014. Disponível em:

$<$ http://www.derechoycambiosocial.com/revista036/FEMINISMO.COM.pdf $>$. Acesso em 21 de maio de 2017.

RUZYK, Carlos Eduardo Pianovski. Institutos Fundamentais do Direito Civil e liberdade(s): repensando a dimensão funcional do contrato, da propriedade e da família. Rio de Janeiro: GZ Ed., 2011. 
SALIH, Sara. Judith Butler e a Teoria Queer. Tradução e notas: Guacira Lopes Louro. 1 ed. Belo Horizonte: Autêntica Editora, 2017.

SPARGO, Tamsin. Foucault e a teoria queer: seguido de Ágape e êxtase: orientações pósseculares. Tradução Heci Regina Candiani. Belo Horizonte: Autêntica Editora, 2017.

TEPEDINO, Gustavo. A tutela da personalidade no ordenamento civil- constitucional brasileiro. In:Temas de Direito Civil. Rio de Janeiro, 2004, t.1.

TRANSGENDER EUROPE. Trans Murder Monitoring. Disponível em:

$<$ https://transrespect.org/en/tmm-update-trans-day-remembrance-2017/>. Acesso em $08 \mathrm{de}$ julho de 2018.

WOODWARD, Kathryn. Identidade e diferença: uma introdução teórica e conceitual. In: SILVA, Tomaz Tadeu da. Identidade e diferença: a perspectiva dos estudos culturais. 15 ed. Petrópolis: Vozes, 2014. 